\title{
THE IMPACT OF ENERGY CONSUMPTION ON ECONOMIC GROWTH: THE CASE OF CHINA
}

\author{
SEK, S. K. \\ School of Mathematical Sciences, Universiti Sains Malaysia; 11800 Minden, Penang, Malaysia \\ e-mail: sksek@usm.my; phone: +60166551152; fax: +6046570910 \\ (Received 24 $4^{\text {th }}$ Nov 2016; accepted $28^{\text {th }}$ Mar 2017)
}

\begin{abstract}
Energy resources are important sources used in production. The consumption of energy resources is closely linked to the economic development and the environmental quality. In this paper, empirical analyses are conducted to reveal how energy consumption can affect economic growth (GDP) directly and indirectly through its impact on environmental quality. The study is focused on China, an economy that is highly energy intensive and the second largest economy in the World. Applying linear and threshold cointegration tests, our results reveal significant long-run relationship in the model with GDP as dependent factor and the regressors of energy consumption and carbon dioxide emissions. Our estimation results show that energy consumption has direct positive effect on economic growth but it may have larger negative effect on economic growth indirectly through higher carbon dioxide emissions.
\end{abstract}

Keywords: GDP, environmental degradation, threshold cointegration, asymmetric effect

\section{Introduction}

Energy resources are important sources for production which may stimulate economic growth especially for countries that are highly energy intensive. On the other hand, energy consumption through industrial activities may generate toxic wastes and gases which are harmful to environmental health and cleanliness.

The research on the impact of energy consumption on economic growth is broad and there are on-going researches on this topic because previous studies found no consensus on the relationship between energy consumption and economic growth. Previous results reported different results for different countries, time periods, methodology applied and variables used. Such differences may also due to country specific characteristics.

In this study, we specify the investigation in China, a country that emphasizes on industry development and is highly energy intensive. Our main objective is to reveal is there any long-run relationship between energy consumption and growth in China. In addition, we also investigate how energy consumption affects economic growth directly and indirectly. Applying the linear and threshold cointegration tests, we detect long-run relationship in our model. Our threshold regression and cointegrating model reveal that energy consumption has positive direct impact to stimulate growth. However, it has larger negative impact on growth through carbon dioxide emissions in the long-run.

The remaining paper is organized as follows: section 2 provides review on literature; section 3 explains the data and methodology; section 4 discusses the results and section 5 summarizes the findings.

\section{Literature review}

\section{Theoretical review}

According to economic theories, energy (consumption) and economic activities/ growth are closely related. Amadeh and Kafi (2015) provided a theoretical review on 
the relationship. As indicated in biophysical growth model by Ayres and Nair (1984), energy is the only driver of growth as both labor and capital need to consume energy to be functioning. Conversely, neoclassical economists stated that energy has no direct effect on economic growth but has indirect effect through labor and capital. Both labor and capital are the main factors but energy only plays a small role as intermediate input. However, highly consuming energy resources such as fossil fuels to boost economic growth may cause to higher pollution. The air pollution through carbon dioxide emissions is one of the greenhouse gasses emissions due to fuel consumption in manufacturing, trade, service and housing sectors (Amadeh and Kafi, 2015). In the neoclassical framework by Stern and Cleveland (2004) discussed the relationship between energy and production may influenced by substitution between energy and other inputs, changes in technology, changes related to energy factor combination, products combination and also changes in other inputs combination.

Also, as discussed in Bozkurt and Akan (2014), energy related factors (energy production, consumption, density, status and price of energy) have crucial impacts on the trend of carbon dioxide emissions. These factors are the engine of industrial development and growth but they may cause to reverse effect on environment (Alkhathlan and Javid, 2013). In the progress of growth, economy encounters with the environmental degradation and climate change which may be harmful to the nature, people and economies. Such trade-offs necessitate environmental policy actions to be implemented at local, national and global levels to reduce the adverse effect of energy consumption and growth. The environmental policies research has led to the formation of environmental Kuznets curve theory on the relationship between economic growth and environmental degradation (Grossman and Krueger, 1991). This theory formulates the impact of economic growth on environmental degradation in an inverted-U curve, i.e. higher growth leads to higher environmental degradation until reaching the optimum point. After this point, higher income per capita is associated with lower environmental deterioration (Niu and $\mathrm{Li}, 2014$ ). EKC can be explained by production scale input rates, types of industries, changes in input variety and emission changes in input (Stern, 2003).

\section{Empirical findings}

The relationship among energy consumption, gases emissions and economic growth has attracted many researches and attentions for environmental issue/ policy analysis and sustainable growth. The literature studies in this area can be classified into three main strands (Amadeh and Kafi, 2015; Bozkurt and Akan, 2014; Acaravci and Ozturk, 2010). The first strand focused on the relationship between economic growth and environmental pollution on testing the validity of EKC hypothesis. Grossman and Krueger (1991) were the first to conduct testing on the EKC hypothesis for the data of U.S. Since then, the EKC hypothesis was carried out broadly using linear and nonlinear approaches, panel and time series analyses and variety of emissions across countries and time frames. However, this strand of studies leads to inconclusive findings. Some studies reveal inverted-U curve of EKC (among them are Galeotti and Lanza, 1999; Franklin and Ruth, 2012; and Karakas, 2014). Other studies fail to detect the validity of EKC (for instance Boopen and Vinesh, 2011; Huang et al., 2008; and Charfeddine and Ben Khediri, 2015). Some studies investigated the causal relationship between GDP and carbon dioxide emissions. Many studies used carbon dioxide emissions to proxy for environmental degradation and observed that such emissions accounted for $60 \%$ of the 
greenhouse gases emissions effect (Ozturk and Acaravci, 2010). Other variables used to proxy for environmental degradation include sulphur dioxide per capita, particle pollution (PM10), air pollution and water pollution.

The second strand focused on the relationship between economic growth and energy consumption. This strand of studies was pioneered by Kraft and Kraft (1978) and a review on the related literature was given in Payne (2010) and Ozturk (2010). Ozturk (2010) discussed the four types of hypothesis on the relationship: (1) neutrality hypothesis - no causal relationship; (2) conservation hypothesis - uni-directional causality effect from economic growth to energy consumption; (3) growth hypothesis uni-directional causality effect from energy consumption to economic growth; (4) feedback hypothesis - bi-directional causality between energy consumption and economic growth. Only few papers reported no relationship in their studies, for instance Halicioglu (2009) and Soytas and Sari (2009). The second category relationship was found in Aqeel and Butt (2001) and Narayan and Smyth (2005). The third group relationship was revealed in Tsani (2010), Menyah and Rufael (2010), and Lee and Chien (2010). The bi-directional relationship was found in studies by Ansgar et al. (2010), Erda et al. (2008) and Apergis and Payne (2009).

The third strand studies the output-energy or output-pollution relationship, the combination of the first and second strand of studies. Investigating on the relationship on these three variables, previous studies reported different results. However, majority studies detect cointegrating relationship in their models. Among them, Bloch et al. (2012) and Jafari et al. (2012) found that both GDP and energy consumption contribute to positive effect on pollution (carbon dioxide emissions). On the other hand, Omri (2013) reported a positive impact from GDP but negative impact from financial development and capital on carbon dioxide emissions in MENA countries. Alam et al. (2014) reported that energy consumption and financial development cause to higher carbon dioxide emissions in Malaysia. Other recent researches that detect relationship among the three variables include Wolde (2016), Alege et al. (2016) and Chindo et al. (2015).

The differences results found in previous studies may due to data, estimation approaches and omitted variables bias (Stern and Common, 2001; Toman and Jemelkova, 2003; Dinda, 2004; Stern, 2004; and Yang and Zhao, 2014). According to Ozturk (2010), the differences may also due to country characteristics.

\section{Background study - China}

China as the second largest economy in the world has experienced rapid growth of more than $9 \%$ per year since the 'reform and opening-up' policy has implemented in late of 1980s (Wang et al., 2014). However, such rapid growing progress poses challenges in terms of sharp increases in energy consumption which causes to the increasing of carbon dioxide emissions. As reported by International Energy Outlook (2016), U.S. and China are the two largest energy-related carbon dioxide emitting countries which accounted for $40 \%$ of the globally emissions in 2012. As discussed in Leggett (2011), the World Bank has approximated the loss caused by air and water pollution in China to be US\$100 billion per year or 5.8\% of GDP in year 2007. Such causes and consequences have triggered the ultimate need for the government to take immediate action in balancing the economic growth and quality of life/ environmental quality by monitoring the energy consumed. The government has realized on the importance to reduce the greenhouse gases emissions and pollution problems due to 
energy-related activities and human activities through its national and international policies. At national planning, China has slowly moved to less energy-intensive industries. China has also integrated its climate action into its Five-Year Economy Plan in achieving a 'harmonious society' with lesser environmental problem through slower economic growth.

China also committed to the international climate policies. China has committed to the Intended Nationally Determined Contributions (INDCs) in reducing the greenhouse gases emissions by targeting its peaks on carbon dioxide emissions by 2030 and trying effort to achieve an earlier peak if possible. China also seeks to achieve the target of $20 \%$ nonfossil energy use in 2030. China has obliged to the 2009 Copenhagen Accord to achieve reduction of $40-45 \%$ in carbon intensity by year 2020. As reported in International Energy Outlook (2016), the energy efficiencies through technology in building and transportation sectors help to curb the rate of energy consumption in China (Leggett, 2011).

\section{Data and methodology}

The study focuses the analyses on China. Three variables are used which include carbon dioxide emissions $(\mathrm{kt})\left(\mathrm{CO}_{2}\right)$, as a proxy for environmental degradation, gross domestic product (US\$) (GDP) proxy for economic development and primary energy consumption (millions tons of oil equivalent) (EC). The data are in yearly basis, ranging from year 1966 to 2015. All data are collected from Datastream and are transformed into $\log$ form for consistency ( $\mathrm{LCO}_{2}$, LEC and LGDP). Figure 1 shows the plots of these three variables in levels and logarithms form. Panel (a) shows that the carbon dioxide emissions in China before 1970's were very low. The emissions show increasing trend since after 1970's and the increment was larger in early 2000's. On the other hand, panel (b) and panel (c) respectively show that energy consumption and GDP exhibit extraneous increment since early 2000's. Such increments are clear using levels data but not so clear using logarithms or percentage increment. Combining these plots, we observe some similarities on these three variables, i.e. they show increasing trend; they show large increment in early 2000's. These similarities suggest a close relationship on these variables and further investigation should be conducted through regression analysis.

To proceed with our analysis, we conduct the regression based on the following condition:

$$
L G D P_{t}=f\left(L E C_{t}, L C O 2_{t}\right)
$$

This leads to the following long-run relationship:

$$
L G D P_{t}=\alpha_{0}+\alpha_{1} L E C_{t}+\alpha_{2} L C O 2_{t}+u_{t}
$$

The investigation is divided into two parts. In the first part, we perform both linear and threshold cointegration tests to detect possibly long-run relationship in (Eq.1). Prior to the cointegration tests, unit-root tests are performed to check the properties of the variables. If all variables are stationary at first differenced and integrated with the same 
order, i.e. I(1), one may proceed to test for the long-run relationship using cointegration tests. In the second part, we proceed with the estimation on the long-run relationship.

Before conducting the preliminary tests and estimations, all data are transformed into $\log$ form for consistency ( $\mathrm{LCO}_{2}$, LGDP and LEC). Prior to the estimation, unit-root tests of Phillips-Perron (PP) and Kwiatkowski-Phillips-Schmidt-Shin (KPSS) are performed to check for the stationarity of variables. In case the variables are nonstationary at levels and show the same number of integration, we may proceed with the testing of cointegration, i.e. whether the combination of these variables are stationary. For such purpose, the cointegration tests of Engle-Granger (EG) and Phillips-Ouliaris (PO) are performed to detect the long-run relationship between dependent variable $\left(\mathrm{LCO}_{2}\right)$ and independent variables (LGDP and LEC). Both EG and PO are linear cointegration tests by assuming symmetric in the adjustment process to the long-run level, such tests may have low power in the detection of cointegration in the presence of asymmetric adjustments. For better comparisons, the asymmetric cointegration tests of threshold autoregreesive (TAR) and momentum threshold autoregressive (MTAR) developed by Enders and Granger (1998) and Enders and Siklos (2001) are conducted. Based on the results of these cointegration tests, we proceed with the estimation on the long-run relationship.

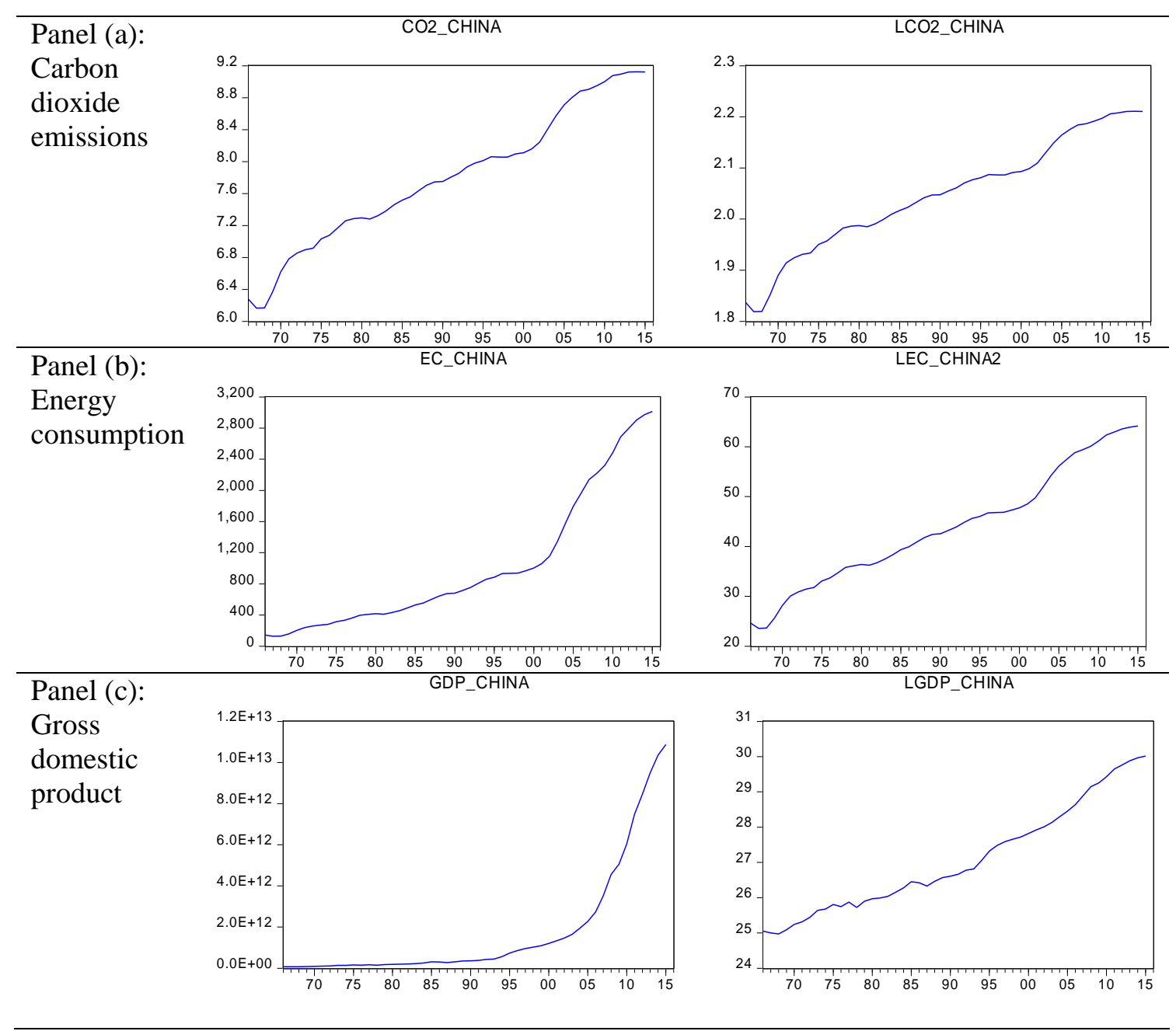

Figure 1. Annual values of carbon emission [kt], energy consumption [millions tons of oil equivalent], and GDP [US\$] on normal and logarithmic scales in the period of 1965-2015 


\section{Threshold cointegration-Enders-Siklos (ES) test}

Two non-stationary variables that are I(1) are cointegrated if the linear combination of them is stationary or $\mathrm{I}(0)$. Such linear combination is termed as a long-run equilibrium relationship. In our case with three variables, LGDP, LCO2 and LEC in (Eq.1) are said to be cointegrated if the linear combination of them $u_{t}=L G D P_{t}-\alpha_{0}-\alpha_{1} L E C_{t}-\alpha_{2} L C O 2_{t} \quad$ is stationary or $u_{t} \square I(0)$. The idea of cointegration test is to test if the error term is $\mathrm{I}(0)$. Previous studies applied the linear cointegration tests (for instance, Johansen test and Engle-Granger test) to detect the long-run relationship in the model. These tests assume symmetric adjustment in the error term. Therefore, in the presence of asymmetric adjustment in the error term, the linear cointegration tests may have low power to weakly detect long-run relationship in the model. To overcome this problem, the threshold cointegration test developed by Enders and Granger (1998) and Enders and Siklos (2001) are conducted. The threshold cointegration test is based on the threshold autoregressive (TAR) and threshold autoregressive (MTAR) models which assume the asymmetric adjustment in the error term.

Under the ES test, the error term is specified as follow:

$$
\Delta u_{t}=\rho_{1} u_{t-1}+\rho_{2}\left(1-I_{t}\right) u_{t-1}+\sum_{i=1}^{k} \delta_{i} \Delta u_{t-i}+v_{t}
$$

where $v_{t} \square \operatorname{iid}\left(0, \sigma^{2}\right)$ is the error term obtained from the long-run relation in equation (1); $\Delta u_{t}$ with lags $\mathrm{k}$ are used to correct for the error terms to avoid correlation in error terms; $I_{t}$ is the Heaviside indicator used to indicate the asymmetric adjustment in error terms following the function defined. Under the TAR model, the function of error term is defined to be:

$$
I_{t}=\left\{\begin{array}{lll}
1 & \text { if } & u_{t-1} \geq \tau \\
0 & \text { if } & u_{t-1}<\tau
\end{array}\right.
$$

where the changes of error term is adjusted based on its lagged one value determined by the threshold value, $\tau$. On the other hand, the function of error term under MTAR specification assumed to depend on the changes in the error term:

$$
I_{t}=\left\{\begin{array}{lll}
1 & \text { if } & \Delta u_{t-1} \geq \tau \\
0 & \text { if } & \Delta u_{t-1}<\tau
\end{array}\right.
$$

$\rho_{1}$ and $\rho_{2}$ show the speed of asymmetric adjustments of the changes of error term to its long-run equilibrium level according to the function of error term defined by TAR and MTAR models. The ES test permits hypothesis on cointegration and asymmetric adjustment in (Eq.2) using joint F-test:

(1) Hypothesis for cointegration: $H_{0}: \rho_{1}=\rho_{2}=0$ : no cointegration

(2) Hypothesis for asymmetric adjustment: $H_{0}: \rho_{1}=\rho_{2}:$ symmetric adjustment 
The significance of the F-statistic in cointegration test can refer to the critical values stated in Enders and Siklos (2001). The rejection of null hypothesis indicates that one of the coefficient or both $\rho_{1}$ and $\rho_{2}$ are smaller than zero which leads to the detection of the long-run relation in (Eq.1). Once the long-run relation is detected, one can continue testing for asymmetric adjustment in the error term. Since the null hypothesis is symmetric adjustment, the rejection of the null hypothesis means the existence of the asymmetric adjustment in the error term.

\section{Estimation approaches}

In the presence of long-run relation in (Eq.1), the dynamic ordinary least square (DOLS) is a better choice to replace the traditional least square approach (OLS) as this approach includes leads and lags of first differenced regressors in the equation to control for regressor endogeneity and error serial correlation problems. Under the specification of DOLS, (Eq.1) can be estimated as:

$$
L G D P_{t}=\alpha_{0}+\alpha_{1} L E C_{t}+\alpha_{2} L C O 2_{t}+\sum_{i=-k}^{+k} \varphi_{1 i} \Delta L E C_{t-i}+\sum_{i=-k}^{+k} \varphi_{2 i} \Delta L C O 2_{t-i}+u_{t}
$$

$\sum_{i=-k}^{+k} \varphi_{1 i}$ and $\sum_{i=-k}^{+k} \varphi_{2 i}$ are the coefficients for the leads and lags of first differenced regressors but they are not given/ interpreted as they act as endogeneity and serial correlation corrector. Previous studies show that DOLS performs better compare to OLS and FMOLS (Kao and Chiang, 2000 and Stock and Watson, 1993).

Apart from DOLS, we also consider the threshold regression by considering the effects of breakdates. The breakpoint threshold regression is performed in searching breaks in the sample and can be written as:

$$
\begin{aligned}
L G D P_{t} & =\beta_{1} I\left(t \leq k_{1}\right)\left[c_{0}+a_{0,1} L E C_{t}+a_{0,2} L C O 2_{t}\right] \\
& +\beta_{2} I\left(k_{1}+1 \leq t \leq k_{2}\right)\left[c_{1}+a_{1,1} L E C_{t}+a_{1,2} L C O 2_{t}\right] \\
& +\beta_{3} I\left(k_{2}+1 \leq t \leq T\right)\left[c_{2}+a_{2,1} L E C_{t}+a_{2,2} L C O 2_{t}\right]+u_{t}
\end{aligned}
$$

for two breakdates model where $k_{1}$ and $k_{2}$ are the breakdates. In this study, the sequential determination approach by Bai (1997) is used for searching up to 2 breakdates. The breaks of date $k_{1}$ and $k_{2}$ have divided the sample period into three sub-periods, i.e. $\left(t \leq k_{1}\right),\left(k_{1}+1 \leq t \leq k_{2}\right)$ and $\left(k_{2}+1 \leq t \leq T\right)$.

\section{Results}

Prior to the estimation, unit-root tests and cointegration tests are conducted to check for the properties of variables. Table 1. summarizes the results of unit-root tests. The null hypothesis for Augmented Dicky-Fuller (ADF) test is the series contains unit-root while the null hypothesis for Kwiatkowski-Phillips-Schmidt-Shin (KPSS) test is the series has no unit-root. Therefore, the rejection of null hypothesis indicates that the series is 
stationary under ADF test but not stationary under KPSS test. As observed from Table 1., all series/ variables are not stationary at levels but stationary at first differenced. This means that all variables are integrated with the same order, i.e. I(1). This allows us to proceed with the cointegration to find out if the combination of these variables is stationary using linear and threshold cointegration tests. The null hypothesis states that no cointegration exists in (Eq.1). Table 2. summarizes the results of linear cointegration tests of Engle-Granger (EG) and Phillips-Ouliaris (PO) by assuming linear adjustment in the error term. The Phillips-Ouliaris test (z-statistic) is able to reject the null hypothesis at $10 \%$ significance level to signify the long-run relationship while Engle-Granger test fail to detect any long-run relationship. If the symmetric adjustment of error term is released, will the result change? In answering this question, we compare the results of linear cointegration with the threshold cointegration test based on TAR and MTAR models. Table 3. shows the results of threshold cointegration. The results show the detection of long-run relationship (reject no cointegration) using MTAR specification but not TAR specification. The MTAR specification is also able to reject the null hypothesis of symmetric adjustment, indicating to the asymmetric adjustment in the error term. Since both linear and threshold cointegraton tests lead to the same result, i.e. the existence of long-run relationship in (Eq.1) and there appear possibility on the asymmetric or threshold effect in the relationship, we continue with the estimation by comparing linear cointegrating regression of DOLS and breakpoint threshold regression.

Table 1. Unit-root tests

\begin{tabular}{l|l|l|l|l}
\hline \multirow{2}{*}{ Variable } & \multicolumn{2}{|l|}{ ADF test statistic } & \multicolumn{2}{l}{ KPSS test statistic } \\
\cline { 2 - 5 } & Level & $1^{\text {st }}$ differenced & Level & $1^{\text {st }}$ differenced \\
\hline LCO2_CHINA & -0.8101 & $-3.5844 * *$ & $0.8228 * * *$ & 0.2304 \\
LGDP_CHINA & 2.5932 & $-5.3629 * * *$ & $0.8114^{* * *}$ & 0.1006 \\
LEC_CHINA & 0.3361 & $-3.3210^{* *}$ & $0.8216^{* * *}$ & 0.1468 \\
\hline
\end{tabular}

Table 2. Linear cointegration tests

\begin{tabular}{l|l|l|l}
\hline \multicolumn{2}{l|}{ Engle-Granger test } & \multicolumn{2}{l}{ Phillips-Ouliaris test } \\
\hline tau-statistic & z-statistic & tau-statistic & z-statistic \\
-2.9624 & -14.0334 & -3.7730 & $-24.9575^{*}$ \\
\hline
\end{tabular}

Table 3. Threshold cointegration test

\begin{tabular}{l|l|l|l|l|l}
\hline \multirow{2}{*}{ Model } & \multirow{2}{*}{$\tau$} & $\rho_{1}$ & \multirow{2}{*}{$\rho_{2}$} & \multicolumn{1}{|c}{ Cointegration } & Asymmetric \\
\cline { 5 - 6 } & & & & \multicolumn{1}{c}{$\rho_{1}=\rho_{2}=0$} & \multicolumn{1}{c}{$\rho_{1}=\rho_{2}$} \\
\hline TAR & -0.1674 & $-0.3566 * * *$ & -0.1910 & 4.5102 & 0.9800 \\
MTAR & 0.0602 & $-0.9798 * * *$ & $-0.2208 * *$ & $8.7618 *$ & $8.1162 * *$ \\
\hline
\end{tabular}

The last column in Table 4. is the result using DOLS estimation. The result shows that higher energy consumption stimulates higher economic growth. However, this positive effect is relatively low compared to the negative effect of carbon dioxide 
emissions on growth. As research findings and institutional reports show that energy consumption is the primary factor contributing to higher pollution and greenhouse gases emissions problem, our result implies that energy consumption has a positive direct effect on economic growth (GDP) but its negative indirect effect on growth through higher carbon dioxide emissions leads to larger adverse effect on growth. The total effect of higher energy consumption on growth is negative. However, this result is based on symmetric relation. In order to investigate if the result changes due to threshold effect, we also perform the threshold breakdate regression. Using the sequential determination searching, two breakdates are detected which break our sample into three sample sub-periods (1966-1994, 1995-2007 and 2008-2015). The results of breakdate regression are summarized in Table 4. As observed, the result still remains the same, i.e. energy consumption has smaller positive direct effect on growth but its carbon dioxide emissions (indirect effect of energy consumption) has very large negative effect on growth. This result holds for all three sub-sample periods. Both effects on growth are the highest during 1995-2007 due to the industrialized activities and booming of economic in China. However, the effect of carbon dioxide emissions on growth has declined significantly during 2008-2015 as a result due to the success of the policy maker in controlling the environmental pollution problem.

Table 4. Long-run estimates

\begin{tabular}{l|l|l|l|l}
\hline \multirow{2}{*}{ Variable } & \multicolumn{3}{|c|}{ Coefficient - threshold regression } & \multirow{2}{*}{ Coefficient-DOLS } \\
\cline { 2 - 5 } & $1966-1994$ & $1995-2007$ & $2008-2015$ & \\
\hline $\mathrm{C}$ & $45.4943 * * *$ & $116.7173 * * *$ & $25.1739 * * *$ & $73.0672 * * *$ \\
$\mathrm{LEC}$ & $4.0071 * * *$ & $10.7203 * * *$ & $3.8087 * * *$ & $7.2840 * * *$ \\
$\mathrm{LCO} 2$ & $-21.9708 * * *$ & $-77.8738 * * *$ & $-11.6098 * * *$ & $-45.7833 * * *$ \\
\hline R-square & 0.9982 & 0.9982 & 0.9982 & 0.9913 \\
\hline
\end{tabular}

\section{Conclusion}

China is the largest carbon dioxide and greenhouse gases emitting country and also has the second largest economy after U.S. The environmental issue and pollution problem is always the concern of the government as such problem leads to large losses to the economy and negatively affects the economic growth in China. In this paper, empirical analyses are conducted to reveal the direct and indirect impacts of energy consumption on economic growth in China. In particular, we seek to investigate if energy consumption and carbon dioxide emissions can have long-run determination on economic growth in China. Applying linear and threshold cointegration tests, our results reveal possibly long-run asymmetric relation in the model. The results from DOLS and breakdate threshold regression show that energy consumption has significant positive long-run effect on economic growth directly. However, such effect is relatively small compared to the strong negative effect from carbon dioxide emissions (indirect effect of energy consumption) on economic growth. The results hold under different time frames. We also observe the decline in the determination effect of carbon dioxide emissions on growth, indicating the success of the policymaker in controlling environmental problem and the commitment of China to the international climate policies and obligations.

Acknowledgements. This work is supported by the Research University Grant (RU), (1001/PMATHS/8711312). 


\section{REFERENCES}

[1] Acaravci, A., Ozturk, I. (2010): On the Relationship Between Energy Consumption, $\mathrm{CO}_{2}$ Emissions and Economic Growth in Europe. - Energy Policy 35: 412-5420.

[2] Alam, A. et al. (2014): Environmental Quality Indicators and Financial Development in Malaysia: Unity in Diversity. - Environmental Science and Pollution Research 22: 83928404.

[3] Alege, P.O., Adediran, O.S., Ogundipe, A.A. (2016): Pollutant Emissions, Energy Consumption and Economic Growth in Nigeria. - International Journal of Energy Economics and Policy. 6: 202-207.

[4] Alkhathlan, K., Alam, M.Q., Javid, M. (2012): Carbon Dioxide Emissions, Energy Consumption and Economic Growth in Saudi Arabia: A Multivariate Cointegration Analysis. - British Journal of Economics, Management and Trade 2: 327-339.

[5] Amadeh, H., Kafi, P. (2015): The Dynamic Relationship Among Economic Growth, Energy Consumption and Environment in Iran. - International Letters of Social and Humanistic Sciences 50: 118-128.

[6] Ansgar, B., Dreger, C., Frauke, D.H. (2010): Energy Consumption and Economic Growth: New Insights into the Cointegration Relationship. - Ruhr Economic Papers 190: $1-24$.

[7] Apergis, N., Payne, J.E. (2009): Energy Consumption and Economic Growth: Evidence from the Commonwealth of Independent States. - Energy Economics 31: 641-647.

[8] Aqeel, A., Butt, S. (2001): The Relationship between Energy Consumption and Economic Growth in Pakistan. - Asia Pacific Development Journal 8: 101-110.

[9] Ayres, R., Nair, I. (1984): Thermodynamics and Economics - Physics Today 25: 62-71.

[10] Bai, J. (1997): Estimating Multiple Breaks One at a Time. - Econometric Theory 13: 315352.

[11] Bloch, H., Rafiq, S., Salim, R. (2012): Coal Consumption, $\mathrm{CO}_{2}$ Emission and Economic Growth in China: Empirical Evidence and Policy Responses. - Energy Economics 34: 518-528.

[12] Boopen, S., Vinesh, S. (2011): On the Relationship between CO2 Emissions and Economic Growth: The Mauritian Experience. - University of Mauritius, Mauritius Environment Out-look Report, http://www.csae.ox.ac.uk/conferences/2011EDiA/papers/776-Seetanah.pdf (19.12.2012)

[13] Bozkurt, C., Akan, Y. (2014): Economic Growth, $\mathrm{CO}_{2}$ Emissions and Energy Consumption: The Turkish Case. -International Journal of Energy Economics and Policy 4: 484-494.

[14] Charfeddine, L., Ben Khediri, K. (2015): Financial Development and Environmental Quality in UAE: Cointegration with Structural Breaks. - Renewable and Sustainable Energy Reviews 55: 1322-1335.

[15] Chindo, S.et al. (2015): Energy Consumption, $\mathrm{CO}_{2}$ Emissions and GDP in Nigeria. - GeoJournal 80: 315-322.

[16] Dinda, S. (2004): Environmental Kuznets Curve Hypothesis: A Survey. - Ecological Economics 49: 431-455.

[17] Enders, W., Granger, C.W.J. (2014): Unit-Root Tests and Asymmetric Adjustment with an Example Using the Term Structure of Interest Rates. - Journal of Business and Economic Statistics 16: 304-311.

[18] Enders, W., Siklos, P.L. (2001): Cointegration and Threshold Adjustment. - Journal of Business and Economic Statistics 19: 166-176.

[19] Erda, G., Erda, H., Esengun, K. (2008): The Causality between Energy Consumption and Economic Growth in Turkey. - Energy Policy 36: 3838-3842.

[20] Franklin, R. S., Ruth, M. (2012): Growing Up and Cleaning Up: The Environmental Kuznets Curve. - Applied Geography 1: 29-39. 
[21] Galeotti, M., Lanza, A. (1999): Richer and Cleaner? A Study on Carbon Dioxide Emissions in Developing Countries. - Energy Policy 27: 565-573.

[22] Grossman, G. M., Alan, K. (1991): Environmental Impact of a North American Free Trade Agreement. - Working Paper, 3194. Cambridge, MA: National Bureau of Economic Research.

[23] Halicioglu, F. (2009): An Econometric Study of $\mathrm{CO}_{2}$ Emissions, Energy Consumption, Income and Foreign Trade in Turkey. - Energy Policy 37: 1156-1164.

[24] Huang, W. M., Lee, G. W. M., Wu, C. (2008): GHG Emissions, GDP Growth and the Kyoto Protocol: A Revisit of Environmental Kuznets Curve Hypothesis. - Energy Policy 36: 239-247.

[25] Jafari, Y., Othman, J., Nor, A. H. S. M. (2012): Energy Consumption, Economic Growth and Environmental Pollutants in Indonesia. - Journal of Policy Modeling 34: 879-889.

[26] Kao, C., Chiang, M. (2000): On the Estimation and Inference of a Cointegrated Regression in Panel Data. - Advances in Econometrics, Research 15: 179-222.

[27] Karakas, A. (2014): Economic Growth- $\mathrm{CO}_{2}$ Emission Relationship in OECD and NonOECD Countries: A Panel Data Analysis for the Period Between 1990-2011. - The International Journal of Humanities and Social Studies 2: 57-64.

[28] Kraft, J., Kraft, A. (1978): On the Relationship between Energy and GNP. - Journal of Energy and Development 3: 401-403.

[29] Lee, C.C., Chien, M.S. (2010): Dynamic Modelling of Energy Consumption, Capital Stock, and Real Income in G-7 Countries. - Energy Economics 32: 564-581.

[30] Leggett, J.A. (2011): China's Greenhouse Gas Emissions and Mitigation Policies. Congressional Research Service.

[31] Menyah, K, |Wolde-Rufael, Y. (2010): $\mathrm{CO}_{2}$ Emissions, Nuclear Energy, Renewable Energy and Economic Growth in the US. - Energy Policy 38: 2911-2915.

[32] Narayan, P.K., Smyth, R. (2005): Electricity Consumption, Employment and Real Income in Australia Evidence from Multivariate Granger Causality Tests. - Energy Policy 33: 1109-1116.

[33] Niu, H., Li, H. (2014): An Empirical Study on Economic Growth and Carbon Emissions of G20 Group. - International Conference on Education Reform and Modern Management.

[34] Omri, A. (2013): CO2 Emissions, Energy Consumption and Economic Growth Nexus in MENA Countries: Evidence from Simultaneous Equations Models. - Energy Economics 40: 657-664.

[35] Ozturk, I. (2010): A Literature Survey on Energy-Growth Nexus. - Energy Policy 38: 340-349.

[36] Ozturk, I., Acaravci, A. (2010): $\mathrm{CO}_{2}$ Emissions, Energy Consumption and Economic Growth in Turkey. - Renewable and Sustainable Energy Reviews, Elsevier 14: 32203225.

[37] Payne, J.E. (2010): Survey of the International Evidence on the Causal Relationship between Energy Consumption and Growth. - J. Econ. Stud. 37: 53-95.

[38] Soytas, U., Sari, R. (2009): Energy Consumption, Economic Growth, and Carbon Emissions: Challenges Faced by an EU Candidate Member. - Ecological Economics 68: 1667-1675.

[39] Stern, D. I., Common, M. S. (2001): Is there an Environmental Kuznets Curve for Sulphur? - Journal of Environmental Economics and Environmental Management 41: 162-178.

[40] Stern, D.I. (2004): The Rise and Fall of the Environmental Kuznets Curve. - World Development 32: 1419-1439.

[41] Stern, D.I. (2013): The Environmental Kuznets Curve. - The International Society for Ecological Economics, http://isecoeco.org/pdf/stern.pdf.

[42] Stern, D. I., Cleveland, C. J. (2004). Energy and Economic Growth. - Rensselaer Working Papers in Economics, No. 0410. 
[43] Stock, J.H., Watson, M.W. (1993): A simple Estimator of Cointegrating Vectors in Higher Order Integrated Systems. - Econometrica 61: 783-820.

[44] Toman, M. A., Jemelkova, B. (2003): Energy and Economic Development: An Assessment of the State of Knowledge. - The Energy Journal 93-112.

[45] Tsani, S.Z. (2010): Energy Consumption and Economic Growth: A Causality Analysis for Greece. - Energy Economics 32: 582-590.

[46] Wang, H., Yang, X., Ou, X. (2014): A Study on Future Energy Consumption and Carbon Emissions of China's Transportation Sector. - Low Carbon Economy 5: 133-138.

[47] Wolde, E.T., Mulugeta, W., Hussen, M.M. (2016): Energy Consumption, Carbon Dioxide Emissions and Economic Growth in Ethiopia. - Global Journal of Management and Business Research B. 16: 1-10.

[48] Yang, Z., Zhao, Y. (2014): Energy Eonsumption, Carbon Emissions, and Economic Growth in India: Evidence from Directed Acyclic Graphs. - Economic Modelling 38: 533-540. 